\title{
Characterization and UV Treatment of Cooling Water from an Oil Refinery
}

\author{
Jimoh Oladunni Haolat ${ }^{\mathrm{a}}$, Abraham George ${ }^{\mathrm{b}}$, Mabrok Issa ${ }^{\mathrm{b}}$, Mikael Berthod ${ }^{\mathrm{b}}$, Kean Wang ${ }^{\mathrm{a}}$ * \\ ${ }^{a}$ The Petroleum Institute, Abu Dhabi, PO Box 2533, UAE \\ ${ }^{b}$ Takreer Research Center, Abu Dhabi, PO Box 3593, UAE
}

\begin{abstract}
The cooling water from a local oil refinery was sampled, analyzed and experimentally treated with UV light irradiation at a wavelength of $\sim 254 \mathrm{~nm}$. Total Organic Carbon (TOC), Biological Oxygen Demand (BOD), Chemical Oxygen Demand (COD) and bacteria count (BC) were analyzed for the water samples over years to monitor the water quality. The experimental results showed that: 1) The cooling water quality (e.g. organic matters) varies significantly over the years' operation, probably due to the change in weather (mainly the temperature); 2) The UV treatment was highly effective for the disinfection of cooling water. Within a 24 hour treatment period, it was observed that the bacteria count decreased from $3890 \mathrm{cfu} / \mathrm{ml}$ to practically undetectable, which is consistent with the UV/Vis analysis that the absorbance at $254 \mathrm{~nm}$ was decreased significantly over the time. The degradation of chemicals by UV was also observed in the experiment.
\end{abstract}

Keywords: UV, refinery water, water analysis, UV/Vis, cooling water, water treatment.

\section{Introduction}

The bio-fouling and corrosion present significant challenges to the cooling water system in oil and gas industry [1]. In a local refinery of Abu Dhabi National Oil Company (ADNOC), the closed loop of the fresh cooling water has a circulation rate around $400 \mathrm{~m}^{3} /$ hour. Over the years, bacteria/microorganisms grow in the system (biofoulings) and become resistant to such conventional chemicals as hypochlorine, biocides, and inhibitors, etc., and present serious threat to the heat transfer efficiency and equipment life. The rapid growth of bacteria also requires frequent replenishing of fresh water (as well as the chemical additives) in the system. In addition to environmental hazards and costs, governmental regulations also prevent the high dosage of such chemicals in the cooling water system. Therefore, there is an urgent need to improve the cooling water quality while eliminating/reducing the use of chemicals to alleviate the environmental burdens [2].

Natural Organic matter (NOM) which are usually present in water bodies break down to smaller molecules such as organic acids and aldehydes which are easily assimable by bacteria when excessive chlorine dosing occurs. This serves as a source of nutrients. Hence in order to reduce bacteria activities present in the cooling water, the amount of bacteria and organic compounds have to be monitored.
UV germicidal irradiation (UVGI) is a physical process that transfers electromagnetic energy from a UV lamp which alters the DNA and RNA of an organism with the most effective wavelength of $\sim 250 \mathrm{~nm}$. The adsorption of UV irradiation by microorganisms leads to the reaction of thymine (present in DNA and RNA) with UV light producing dimers which render the microorganism sterile [3]. The effectiveness of UV disinfection is dependent on intensity of UV irradiation, contact time of the microorganism, and the composition of the water sample[4]. A major challenge of UV disinfection system is the inability to provide complete residual removal. A photocatalyst (e.g. $\mathrm{TiO}_{2}$ ) may be used in combination to disintegrate the bacteria residuals and therefore, provide a complete solution.

It has also been reported that UV irradiation can be strongly absorbed by NOM within the wavelength range of $200-400 \mathrm{~nm}$ resulting in a decrease in molecular size of organic carbons, Total organic carbon (TOC) and UV absorbance[5]. The adsorption of photons by NOM for long irradiation times or at high intensities leads to degradation of NOM to low molecular weight organic acids and subsequently mineralization to $\mathrm{CO}_{2}$, thus, reducing the source of nutrient to bacteria[5]. Studies of $\mathrm{UV}_{254}$ irradiation effects of assimable organic carbon (AOC) concentration have produced different views. Lehtola et al reported that the AOC concentration reduced whilst Shaw et al reported that it increased insignificantly[6, 7].

${ }^{*}$ Corresponding author

E-mail: kwang@pi.ac.ae

(C) 2015 International Association for Sharing Knowledge and Sustainability

DOI: 10.5383/swes.7.02.006 
The aims of this study were to investigate the effects of UV irradiation on the industrial cooling water and to determine the rate of bacteria disinfection in a bench scale UV reactor.

\section{Experimental}

Sample collection \& Analysis

Cooling water samples were collected from the sampling point of the buffer tank $\left(10 \mathrm{~m}^{3}\right)$ in the refinery. The sampling was done monthly throughout the year. About 1 liter of cooling water was filled into a pre-sterilized opaque plastic bottle. The bottle was then placed in a cool box filled with ice and sent for rapid analysis.

Table 1: Lab Analysis for the Refinery Cooling Water Samples

\begin{tabular}{|l|l|l|l|l|l|}
\hline Test & BOD5 & COD & TOC & $\begin{array}{l}\text { Total } \\
\text { Bacteria } \\
\text { Count }\end{array}$ & $\begin{array}{l}\text { Metal } \\
\text { Ions }\end{array}$ \\
\hline Method & $\begin{array}{l}\text { APHA } \\
\text { 5210 B }\end{array}$ & $\begin{array}{l}\text { APHA } \\
\text { 5220 B }\end{array}$ & $\begin{array}{l}\text { APHA } \\
\text { 5310 B }\end{array}$ & $\begin{array}{l}\text { APHA } \\
\text { 9215 B }\end{array}$ & $\begin{array}{l}\text { APHA } \\
\text { 3210 B }\end{array}$ \\
\hline
\end{tabular}

The analysis of $\mathrm{BOD}_{5}, \mathrm{COD}$, TOC and Bacteria count were performed on the refinery water/ treated refinery water according to the standard protocols listed in Table 1. The analysis of UV-Vis was performed on an Agilent Cary 5000 Spectrophotometer.

\section{UV irradiation Experiment}

A KTUV-02 UV reactor was used in bench scale experiment setting, as shown in Figure 1 below (model: UV-A-1GPM, 11 Watt. Local supplier: Kontec CO LLC Dubai, UAE http:www.kontec.ae). The reactor is a 403 Stainless Steel cylindrical chamber with $\sim 500 \mathrm{~mm}$ in Length and $80 \mathrm{~mm}$ in diameter. The UV lamp was placed in a quartz tube (sleeves) which is fixed in the center of the reactor. The average UV intensity is $\sim 120 \mathrm{~mW} / \mathrm{cm}^{2}$ with an emission peak wavelength of $\sim 254 \mathrm{~nm}$. A peristatic pump was used to circulate the cooling water between the reactor and a 5 liter storage tank. The water sample was directly taken from the refinery. Irradiation experiments were carried out at the room temperature of $23 \pm 2{ }^{\circ} \mathrm{C}$.

In order to evaluate the effectiveness of UV irradiation on the disinfection of the cooling water, the following experiments were performed.

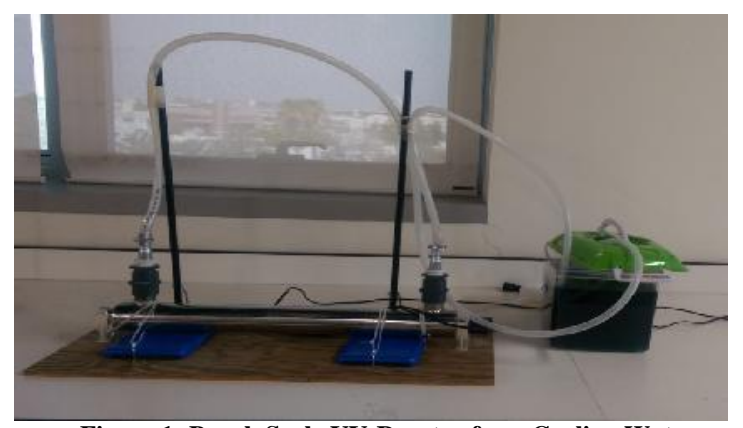

Figure 1: Bench Scale UV-Reactor for a Cooling Water Recirculating System

\section{Total Organic Carbon}

TOC concentrations were analyzed using O-I-Analytical Aurora Model 1030 which uses a wet oxidation method with non-dispersive infrared (NDIR) detection technique.

\section{Biological Oxygen Demand}

The BOD analysis was performed using a 5 day test period with the dissolved oxygen (DO) measured before and after incubation period. The samples were incubated at a temperature of $20 \pm 1^{\circ} \mathrm{C}$ in a dark environment to prevent algae growth. After incubation of 5 days the initial and final dissolved oxygen were analyzed using azide modification titrimetric method[8]. The difference between the initial and final dissolved oxygen was BOD5.

\section{Chemical Oxygen Demand}

The COD analysis was carried out using a Hach COD digestion solution vial which used dichromate as the oxidizing solution. The homogenized water sample together with a blank solution was digested for two hours at a temperature of $150^{\circ} \mathrm{C}$ in a digestion reactor (Hach DRB 200) to ensure reproducibility of the result. The experiment was performed in thrice to average the result.

\section{UV/Vis analysis}

UV/Vis NIR spectroscopy (model: Agilent Cary 5000) was used to measure the absorbance of the sample water at various wave lengths. $\mathrm{UV}_{254}$, also known as the Spectral Absorption Coefficient (SAC), is a water quality test parameter which utilizes light at the UV $254 \mathrm{~nm}$ wavelength to be able to detect organic matter in water and wastewater. This is due to the fact that most organic compounds absorb light at the UV $254 \mathrm{~nm}$ wavelength. UV/Vis spectra have been widely used in qualitative/quantitative determination of such water qualities as $\mathrm{BOD} / \mathrm{COD} / \mathrm{TOC}$, etc. [9].

\section{Results and Discussion}

Figure 2 shows the overall UV-spectra of the cooling water sample after a 24 hour's UV treatment. It can be observed that the overall water quality improved consistently after UV treatment. The decrease in absorbance at $254 \mathrm{~nm}$ wavelength (Figure 3) was approximately $56 \%$ after the $24 \mathrm{~h}$ irradiation period. This slow degradation maybe due to the presence of a high concentration and stable large fraction of humic acid in comparison to fulvic acid was also reported by Allard et al[5]. Generally the structure of aromatic units in humic acids is larger than fulvic acid[5]. In order for a much quicker degradation of NOM which was monitored by TOC reduction (Table 2) a photocatalyst can be introduced into the system as $\mathrm{UV}$ alone is insufficient for a complete disintegration.

It was also observed that TOC reading (Table 2) after UV treatment did not reduce much after a $24 \mathrm{~h}$ treatment, which as also observed in literature. This can be attributed to a number of factors: high concentration of humic acid, nature of the cooling water, etc. $[4,5]$.

However, UV irradiation resulted in a significant drop in bacteria present in cooling water. After a $24 \mathrm{~h}$ disinfection period the bacteria count decreased from $3890 \mathrm{CFU} / \mathrm{ml}$ to 
practically undetectable. This was mainly due to the effect of UVGI which can deactivate virtually all types of bacteria. This is an important result, as the bacteria can be both aerobic and anaerobic, which may not be fully represented by BOD analysis but can be qualitatively observed in the overall UV Spectra as shown in Figure 3.

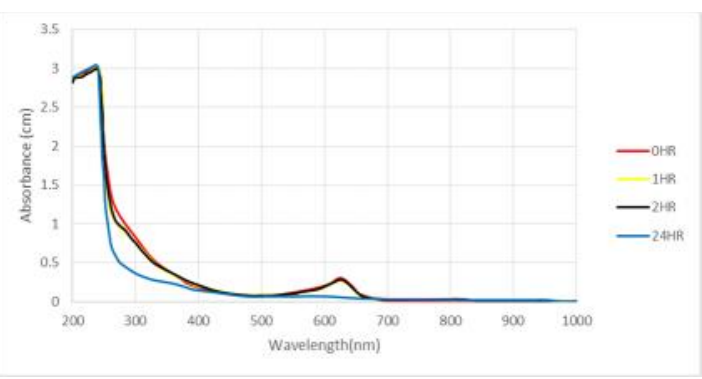

Figure 2: UV Spectra at Various Irradiation Times

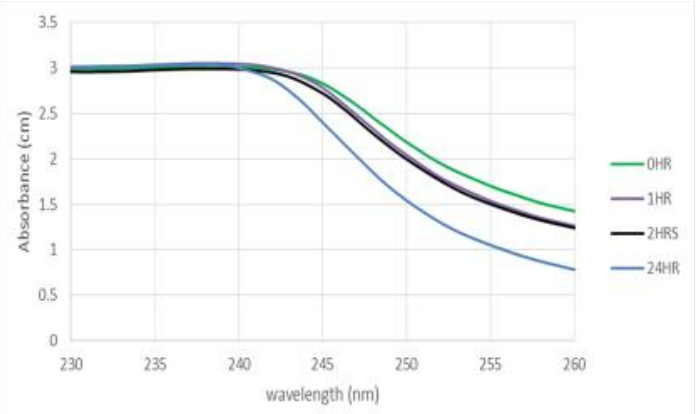

Figure 3: UV Spectra within Wavelength of 230-260nm at Various Irradiation Times

Table 2: Results of TOC (APHA 5310D) for UV Treated Water Sample

\begin{tabular}{|l|l|}
\hline Sample & TOC (PPM) \\
\hline 0 hour & 62.9 \\
\hline 1 hours & 58.1 \\
\hline 2 hours & 59.7 \\
\hline 24 hours & 67.9 \\
\hline
\end{tabular}

Interestingly, it was observed that the results of TOC analysis of the industrial cooling water were dependent on the season of sample collection. The samples analysis collected between the months of February to September was shown in Figure 4 below. We see that TOC was higher during winter in comparison to summer. The long period of strong daylight during the hot summer (where the ambient temperature rises upto $45^{\circ} \mathrm{C}$ ) may be responsible for the increased degradation (or bacteria activities) of humic acid, in comparison to winter (can be as low as $10^{\circ} \mathrm{C}$ ). This trend in TOC was also reported by Allard et al[5]. The dramatic increase in the month of August may be a result of hydrocarbon leak into the system which resulted in a sudden increase in organic matter.

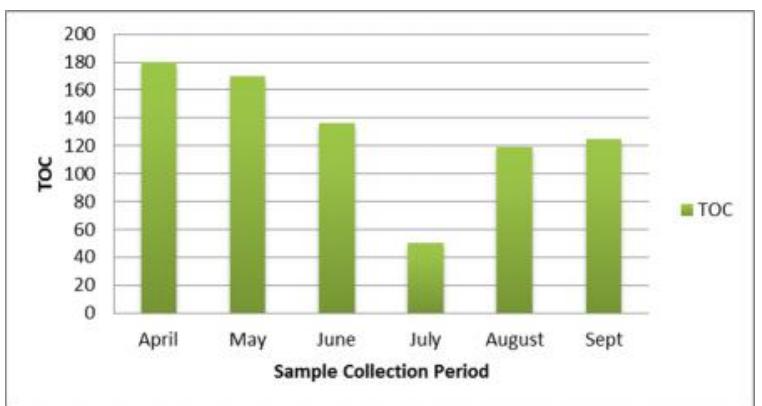

Figure 4: Effects of Season on Total Organic Carbon Reading

From Figure 5, it can be seen that the bacteria count was higher during the cooler period than in summer as well. This may be attributed to the strong sunlight and hot weather in Middle East, which raise the cooling water temperature to a degree that is unfavorable for bacteria growth (the returned cooling water temperature can be as high as $65^{\circ} \mathrm{C}$ ).

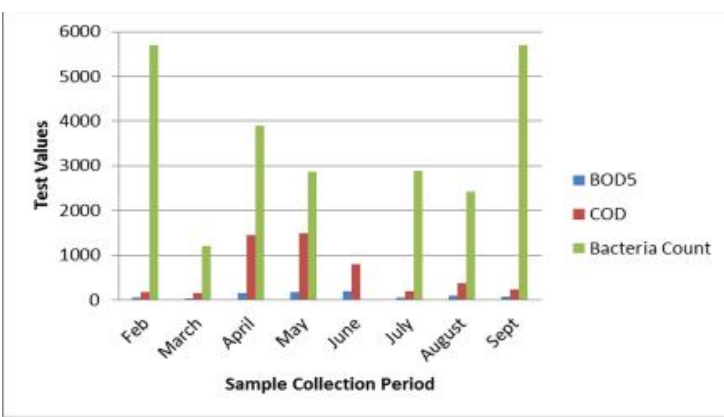

Figure 5: Effects of Season on BOD, COD and Bacteria Count

Finally, we observed that the increase in the residence time of the water sample in the UV reactor resulted in the color change in the cooling water sample from blue to a clear solution. Figure 6 below shows the color change of the industrial water over the 24 hours' treatment.

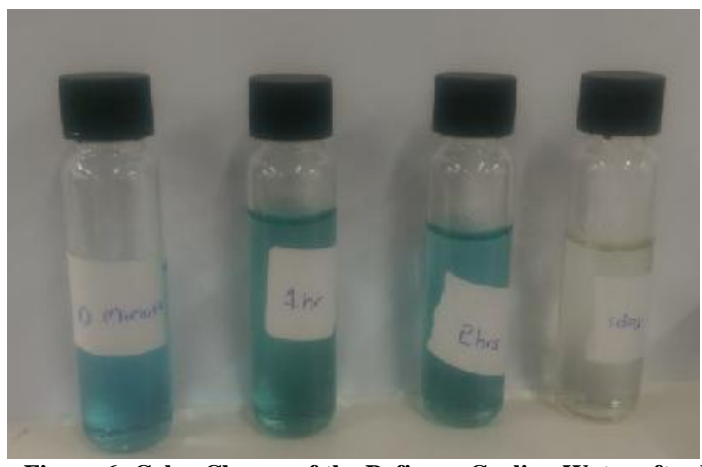

Figure 6: Color Change of the Refinery Cooling Water after UV Treatment

The initial blue color of the cooling water sample was due to the addition of the corrosion inhibitor (molybdate salt) and biocides. The color change of the water sample signifies that the UV irradiation at present level can degrade the salt as well as the organic biocides presenting in the system. This is an interesting result, as it may suggest that the UV treatment can disintegrate such chemicals and make it unnecessary (alleviation) for the use of such chemicals in the cooling water system in the future. 


\section{Conclusion}

The experimental results showed that UV treatment is highly effective in reducing the amount of bacteria present in the industrial cooling water. Moreover, it also can degrade certain chemicals. Cooling water samples properties changed significantly over different seasons of the year. These factors need to be taken into account for the future UV reactor design and operation in the cooling water systems of the oil refinery. More kinetic data of UV irradiation are needed for optimal operation of the UV reactor in the future. The combination of photocatalyst with UV irradiation may improve the system performance in the disinfection of the refinery cooling water.

\section{Acknowledgments}

This project (13704) was funded by Takreer Refinery Company Abu Dhabi (ADNOC). We are grateful for the field engineers who provided us with the system information, technical data and water samples.

\section{References}

[1] G. Alhakimi, L. H. Studnicki, and M. Al-Ghazali, "Photocatalytic destruction of potassium hydrogen phthalate using $\mathrm{TiO} 2$ and sunlight: application for the treatment of industrial wastewater," Journal of Photochemistry and Photobiology A: Chemistry, vol. 154, pp. 219-228, 2003.
[2] Daniel Rubio a, Cristina López-Galindo a, José F. Casanueva b, Enrique Nebot a, "Monitoring and assessment of an industrial antifouling treatment. Seasonal effects and influence of water velocity in an open once-through seawater cooling system," Applied Thermal Engineering, 2014.

[3] W. H. Organisation, "Inactivation (disinfection) processes " in Water Sanitation, ed, pp. 41-62.

[4] U. S. E. P. Agency, "Wastewater Technology Fact Sheet Ultraviolet Disinfection," EPA 832-F-99-064, 1999.

[5] H. B. B.Allard, C. Pettersson and G. Zhang, "Degradation of Humic Substances by UV Irradiation," Environment International, vol. 20, pp. 97-101, 1993.

[6] Markku J. Lehtolaa, Ilkka T. Miettinena, Terttu Vartiainenb,c,Panu Rantakokkob, Arja Hirvonenc, Pertti J. Martikainen, "Impact of UV disinfection on microbiallyavailable phosphorus, organic carbon, and microbial growth in drinking water," Water Research vol. 37 pp. 1064-1070, 2001.

[7] M. J. W. S. Shaw. JP, "Effects of UV Irradiation on Organic matter," JAWWA, vol. 92(4), pp. 157-167, 2000 .

[8] A. O. C. (5000), "5210 BIOCHEMICAL OXYGEN DEMAND (BOD)," ed.

[9] O. Thomas and C. Burgess, UV-visible spectrophotometry of water and wastewater vol. 27: Elsevier, 2007. 